Dikhtyaruk N.N., Poplavskaya E.A., Kurinyenko O.V.

Khmelnitskiy National University,

Khmelnitskiy, Ukraina

E-mail: helen.poplavskaya@gmail.com

\section{CONTACT INTERACTION OF ELASTIC STRIPS WITH INITIAL STRESSES WITH A INFINITE AND FINITE STRINGERS}

UDC 539.3

DOI:10.31891/2079-1372-2019-91-1-6-13

The present article the problems of the contact interaction of infinite and finite elastic stringer with a prestressed elastic strip. The study is performed in the framework of the linearezed theory of elasticity in common form for the theory of large (finite) initial deformations and two variants of the theory of small initial deformations with elastic potential of arbitrary structure. Based on the assume that the stringers load at the same time the vertical and horizontal forces, fair model of bending beams in combination with horizontall elongation. This problem is mathematically formulated as a system of integrodifferential equations of a relatively unknown contact stresses. The system is solved in a closed forms using transformation of Fourier. Expressions of stresses are represented by Fourier integrals with a simple enough structure. Influence of initial stress on the distribution of contact stresses is study and discovered the mechanical effects under the influence of concentrated loads.

Key words: linearezed theory of elasticity, initial (residual) stresses, initial deformations, prestressed elastic strip, transformation of Fourier.

\title{
Introduction
}

In the present paper, within the framework of the linearized theory of elasticity, the problem statement and solving problems of contact interaction of the prestressed elastic strip with infinite and finite stringers are presented. The law of distribution and displacement under the stringer, along of contact line, from the action of the concentrated external force is studied.

All the studies are performed in the general form, adhering to the theory of large (finite) initial strains, for compressible and incompressible bodies with arbitrary elastic potentials. For transition to different theories of small initial deformations it is necessary to introduce the simplifications mentioned in [1].

\section{Isolation of previously unresolved parts of a common problem}

Problems arising up at the transmission of loading from infinite and finite stringers to the elastic stripe the classic theory of stress, again becomes relevant, in the cases when there are initial (residual) stresses in a stripe. The special necessity of their consideration arises up because of their importance at research of constructions in general and especially in connection with planning of constructions of aircrafts. We will notice that initial (residual) stresses practically always are in the elements of constructions and details of machines and can cause deformations, destructions, increase a tendency to the loss of stability and internal friction, etc.

In stringent formulation of contact problems for elastic bodies with initial stresses, there is a need to involve the apparatus of nonlinear elasticity theory, which greatly complicates the construction of analytical solutions. But in the case of large (finite) stresses (deformations) it is possible to be limited to consideration the linearized theory of elasticity [1]. In this article, using the relations of the linearized theory of elasticity [2], the solving of the contact problem for the contact interaction of an infinite and finite stringer with a prestressed strip is presented. The study was carried in a general form for compressible and incompressible bodies for the theory of large (finite) initial strains and two variants of the theory of small initial strains at an arbitrary structure of elastic potential $[6,9]$.

\section{Purpose}

The study of the influence of initial (residual) stresses on the law of distribution and displacement under the stringer, along of contact line. Further consideration of the class the contact problems about the contact interaction of elastic stringers with a prestressed strip. Study out the influence of initial (residual) stresses on the law of distribution of contact stresses under reinforcements the elements along line of direct contact as a result of the action on the elastic stringer of concentrated force. In the case of some elastic potentials of the simplest structure to make carry out numerical calculations and construction of graphs.

\section{Presentation of the main material}

1. The strengthening of the strip an infinite stringer.

Boundary conditions. We assume that in the future always there are four principles, which are fundamental in the theory of contact interaction of bodies with initial stresses and so determine the area of its applications. 
Principle 1. Contact interaction of elastic stringers with infinite (finite) stresses and elastic strip with initial (residual) stresses is transpire after the occurrence of the initial stress state in the strip.

Principle 2. The external load is the acting on an elastic thin stringer causes the initial stresses in the elastic strip to be significantly smaller amount corresponding values to stress state.

Principle 3. The initial stress state of one of the bodies that are in contact interaction has the structure, that in area of theirs contact can (approximately, with a sufficient degree of accuracy) is considers of initial stressed state to be homogeneous.

Principle 4. the Solution of linearized problems theory of the elasticity about the contact interaction of bodies with initial stresses is the only one.

Subject to the conditions $1-4$ in the contact area $L_{k}\left\{a_{k}, b_{k}\right\}$ for elastic stringers and elastic strip with initial (residual) stresses, there are boundary conditions for $y_{2}=0$ :

$$
\begin{gathered}
u\left(y_{1}\right)=u_{1}\left(y_{1}\right) ; \quad v\left(y_{1}\right)=u_{2}\left(y_{1}\right) ; \quad \forall\left(y_{1}\right) \in L_{k}, \\
\frac{\partial u}{\partial y_{1}}=\frac{\partial u_{1}}{\partial y_{1}} ; \quad \frac{\partial v}{\partial y_{1}}=\frac{\partial u_{2}}{\partial y_{1}} ; \quad \forall\left(y_{1}\right) \in L_{k} .
\end{gathered}
$$

The boundary conditions (1) - (2) together with the principles $(1-4)$ and equilibrium conditions:

$$
p=\int_{a_{k}}^{y_{1}} \tau(t) d t,
$$

close the formulation of linearized problems on the contact interaction of elastic stringers (finite, infinite $\left.\left(a_{k}=-\infty ; b_{k}=+\infty\right)\right)$, which reinforce elastic strip.

From the condition of equilibrium the parts of the stringer $\left(-\infty, y_{1}\right)$ (Fig. 1):

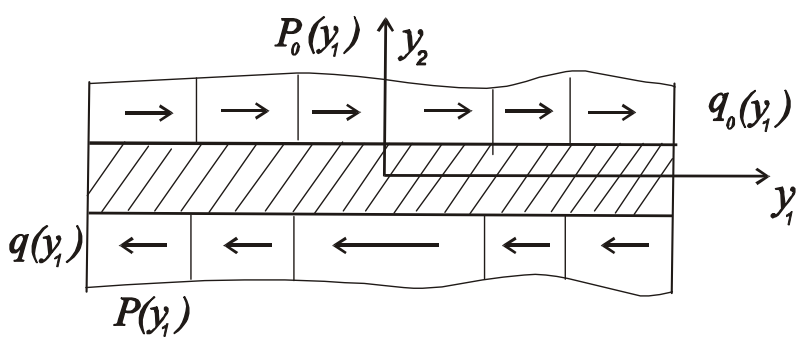

Fig. 1 -- Stringer equilibrium

$$
\begin{gathered}
\frac{d u\left(y_{1}\right)}{d y_{1}}=\frac{1}{E_{1} t} \int_{\infty}^{y_{1}}\left[q(t)-q_{0}(t)\right] d t, \quad\left(-\infty<y_{1}<\infty\right), \\
D \frac{d^{4} v\left(y_{1}\right)}{d y_{1}^{4}}=p\left(y_{1}\right)-p_{0}\left(y_{1}\right)
\end{gathered}
$$

where $D$ - the stiffness of the elastic stringer.

To determination the unknown displacements $u_{1}\left(y_{1}\right)$ and $u_{2}\left(y_{1}\right)$, it is necessary to find the field of elastic displacements and stresses in an infinite elastic strip with initial stresses from the influence of the applied on its surface free of pinching of concentrated normal or tangential a unit force (Fig. 1) of applied at an angle $\alpha$ from the force $P \cdot \delta\left(y_{1}\right)$ [3], here $\delta\left(y_{1}\right)$ the Dirac function; $P$ - force.

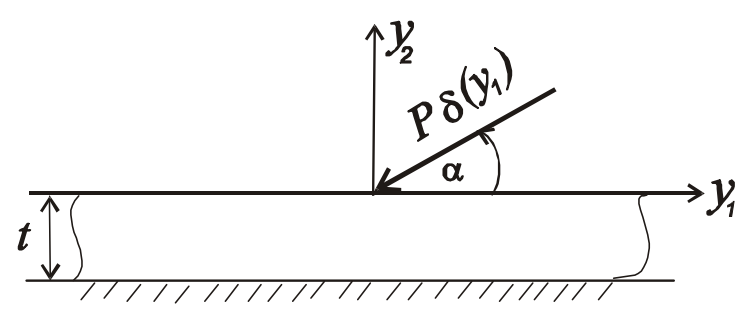

Fig. 2 - Force operation on the stripe 
This problem is solved in the coordinates of the initial deformed state $y_{1}=\lambda_{i} \chi_{i}$ :

$$
u_{m}^{0}=\delta_{i m}\left(\lambda_{i}-1\right)=\delta_{i m}\left(\lambda_{i}-1\right) \lambda_{i}^{-1} y_{i},
$$

where $\lambda_{i}(i=1,2, .$.$) - are the elongations determining displacements of the initial state;$

$\chi_{i}$ - Lagrangian coordinates;

$u_{m}^{0}$ - the displacement, which determines the initial state, in the case of flat deformation;

$s_{0}^{11} \neq 0, s_{0}^{22}=0, \lambda_{1} \neq \lambda_{2}=\lambda_{3}, \lambda_{3}=1$.

The boundary conditions:

$$
\begin{gathered}
\tilde{Q}_{22}\left(y_{1}, 0\right)=-p \delta\left(y_{1}\right) \sin \alpha_{0} ; Q_{11}\left(y_{1}, 0\right)=-p \delta\left(y_{1}\right) \cos \alpha_{0} \\
u_{1}\left(y_{1}-t\right)=0 ; u_{2}\left(y_{1}-t\right)=0 ;-\infty<y_{1}<\infty
\end{gathered}
$$

As a result of solving the previous problem, the functions of influence from the action of a unit normal force for the case of equal roots of constitutive equation $[1,8,10] n_{1}=n_{2}$ :

$$
\begin{aligned}
& h_{11}\left(y_{1}\right)=\frac{1}{\pi} \int_{0}^{\infty} H_{11}(\alpha) \cos \alpha y_{1} d \alpha ; \\
& h_{12}\left(y_{1}\right)=\frac{1}{\pi} \int_{0}^{\infty} H_{12}(\alpha) \sin \alpha y_{1} d \alpha
\end{aligned}
$$

for unequal roots $n_{1} \neq n_{2}$ :

$$
\begin{aligned}
& h_{11}\left(y_{1}\right)=\frac{1}{\pi} \int_{0}^{\infty} \tilde{H}_{11}(\alpha) \cos \alpha y_{1} d \alpha ; \\
& h_{12}\left(y_{1}\right)=\frac{1}{\pi} \int_{0}^{\infty} \tilde{H}_{12}(\alpha) \sin \alpha y_{1} d \alpha .
\end{aligned}
$$

where $h_{i j}(\alpha), i, j=1,2$ are the functions of influence determining displacements of boundary points of the face $y_{2}=0$ of infinite elastic strip with initial (residual) stresses from the unit normal force of core $H_{i j}(\alpha), \tilde{H}_{i j}(\alpha)$ is taken in the form [3,9].

In the case of the action of tangential force for the equal roots $n_{1}=n_{2}$ :

$$
\begin{aligned}
& h_{21}\left(y_{1}\right)=\frac{1}{\pi} \int_{0}^{\infty} H_{21}(\alpha) \sin (\alpha) y_{1} d \alpha \\
& h_{22}\left(y_{1}\right)=\frac{1}{\pi} \int_{0}^{\infty} H_{22}(\alpha) \cos \alpha y_{1} d \alpha
\end{aligned}
$$

for unequal roots $n_{1} \neq n_{2}$ :

$$
\begin{aligned}
& h_{21}\left(y_{1}\right)=\frac{1}{\pi} \int_{0}^{\infty} \tilde{H}_{21}(\alpha) \sin (\alpha) y_{1} d \alpha \\
& h_{22}\left(y_{1}\right)=\frac{1}{\pi} \int_{0}^{\infty} \tilde{H}_{22}(\alpha) \cos \alpha y_{1} d \alpha
\end{aligned}
$$

where the cores $H_{i j}(\alpha)$ and $\tilde{H}_{i j}(\alpha)$ of respectively is taken in the form [3,11].

Now, the based on the principle of superposition, the displacement of the boundary points of the elastic strip with initial (residual) stresses in the direction of the $0 y_{1}$ and $0 y_{2}$ axis from the simultaneous action of the vertical and horizontal forces, for compressible and incompressible bodies in the case an arbitrary structure of elastic potentials in accordance with [3] are written as: 


$$
\begin{aligned}
& u_{1}\left(y_{1}\right)=\int_{-\infty}^{\infty} h_{11}\left(\left|y_{1}-\tau\right|\right) p(\tau) d \tau+\int_{-\infty}^{\infty} h_{12}\left(\left|y_{1}-\tau\right|\right) q(\tau) d \tau ; \\
& u_{2}\left(y_{1}\right)=\int_{-\infty}^{\infty} h_{21}\left(\left|y_{1}-\tau\right|\right) p(\tau) d \tau+\int_{-\infty}^{\infty} h_{22}\left(\left|y_{1}-\tau\right|\right) q(\tau) d \tau .
\end{aligned}
$$

To obtain system of integro-differential equations for the unknown contact stresses, we will take into account the equilibrium conditions of the elastic stringer (4), (5) and expressions for displacements (12). Then the system of integro-differential equations has the form:

$$
\begin{gathered}
D \frac{d^{4}}{d y_{1}^{4}}\left[\int_{-\infty}^{\infty} h_{11}\left(\left|y_{1}-\tau\right|\right) p(\tau) d \tau+\int_{-\infty}^{\infty} h_{12}\left(y_{1}-\tau\right) q(\tau) d \tau\right]=p(\tau)-p_{0}(\tau) \\
E_{1} h \frac{d}{d y_{1}}\left[\int_{-\infty}^{\infty} h_{21}\left(\left|y_{1}-\tau\right|\right) p(\tau) d \tau+\int_{-\infty}^{\infty} h_{22}\left(y_{1}-\tau\right) q(\tau) d \tau\right]=\int_{-\infty}^{\infty}\left[q(\tau)-q_{0}(\tau)\right] d \tau .
\end{gathered}
$$

If only the vertical forces $p_{0}\left(y_{1}\right)$ and $q_{0}\left(y_{1}\right)=0$ act on the stringer, then system (13) is reduced to one integro-differential equation:

$$
D \frac{d^{4}}{d y_{1}^{4}}\left[\int_{-\infty}^{\infty} h_{11}\left(\left|y_{1}-\tau\right|\right) p(\tau) d \tau\right]=p\left(y_{1}\right)-p_{0}\left(y_{1}\right)
$$

Equation (14) describes the bend of an elastic stringer on the elastic strip with initial (residual) stresses.

In the case when under the action of horizontal forces $q_{0}\left(y_{1}\right) \quad\left(p_{0}\left(y_{1}\right)=0\right)$, the elastic stringer only is stretches, we equation is obtained:

$$
E_{1} h \frac{d}{d y_{1}}\left[\int_{-\infty}^{\infty} h_{22}\left(\left|y_{1}-\tau\right|\right) q(\tau) d \tau\right]=\int_{-\infty}^{y_{1}}\left[q(\tau)-q_{0}(\tau)\right] d t .
$$

Equation (15) describes the contact interaction of an elastic stringer on which a horizontal force $q_{0}\left(y_{1}\right)$ with an elastic strip with initial (residual) stresses operates.

For solving the system of integro-differential equations, we use an integral Fourier transforms by $y_{1}$ variable [4]. For this purpose, we first differentiate the second equation on $y_{1}$. Next, we use the convolution theorem for Fourier transform. We obtain the value of the contact stresses in the form:

$$
\begin{aligned}
& q\left(y_{1}\right)=\frac{\mu}{2 \pi} \int_{-\infty}^{\infty}\left[H_{11}^{*}(\alpha) \tilde{q}_{0}(\alpha)-i H_{12}^{*}(\alpha) \tilde{p}_{0}(\alpha)\right] H^{-1}(\alpha) e^{-i \alpha y_{1}} d \alpha, \\
& p\left(y_{1}\right)=\frac{\mu}{2 \pi} \int_{-\infty}^{\infty}\left[\alpha^{2} H_{21}^{*}(\alpha) \tilde{q}_{0}(\alpha)+H_{22}^{*}(\alpha) \tilde{p}_{0}(\alpha)\right] H^{-1}(\alpha) e^{-i \alpha y_{1}} d \alpha,
\end{aligned}
$$

where $H_{i j}^{*} \quad(i, j=1,2)$ is expressed through known functions $H_{i j}$ [5]. Applying the same procedure to the integro-differential equation (14 - 15), the contact stress $p\left(y_{1}\right)$ and $q\left(y_{1}\right)$, we obtain in the form:

$$
\begin{aligned}
& p\left(y_{1}\right)=\frac{\mu}{\pi} \int_{-\infty}^{\infty} \frac{H_{11}(\alpha)}{H(\alpha)} p_{0}(\alpha) e^{-i \alpha y_{1}} d \alpha ; \\
& q\left(y_{1}\right)=\frac{\mu}{\pi} \int_{-\infty}^{\infty} \frac{H_{11}(\alpha)}{H(\alpha)} q_{0}(\alpha) e^{-i \alpha y_{1}} d \alpha .
\end{aligned}
$$

Assume that an elastic thin stringer is loaded with vertical external forces $p_{0}\left(y_{1}\right)=P \cdot \delta\left(y_{1}\right)$ and horizontal forces $q_{0}\left(y_{1}\right)=Q \delta\left(y_{1}\right)$. We denote by $p_{0}(\alpha)=P ; q_{0}(\alpha)=Q$, and then from formulas (18) we obtain expressions for finding the normal contact stresses $p\left(y_{1}\right)$ and tangential stresses $q\left(y_{1}\right)$ : 


$$
\begin{gathered}
q\left(y_{1}\right)=\frac{\mu}{\pi}\left[Q \int_{0}^{\infty} H_{11}^{*}(\alpha) \cdot H^{-1}(\alpha) \cos \alpha y_{1} d \alpha-P \int_{0}^{\infty} H_{12}^{*} H^{-1}(\alpha) \sin \alpha y_{1} d \alpha\right], \\
p\left(y_{1}\right)=\frac{\mu}{\pi}\left[Q \int_{0}^{\infty} H_{21}^{*}(\alpha) \cdot H^{-1}(\alpha) \cdot \alpha^{2} \sin \alpha y_{1} d \alpha-P \int_{0}^{\infty} H_{22}^{*} H^{-1}(\alpha) \cos \alpha y_{1} d \alpha\right] .
\end{gathered}
$$

The numerical calculations were carried out using a computer program in the package Maple 8 , according to the dimensionless quantities $\frac{h}{P} p(t)$ are the normal contact stresses; $\frac{h}{Q} q(t)$ are the tangential contact stresses. For the simplest elastic potentials: harmonic potential, the potential of Bartenev-Khazanovich and potential of Trelora, graphs are constructed (Fig. 3).
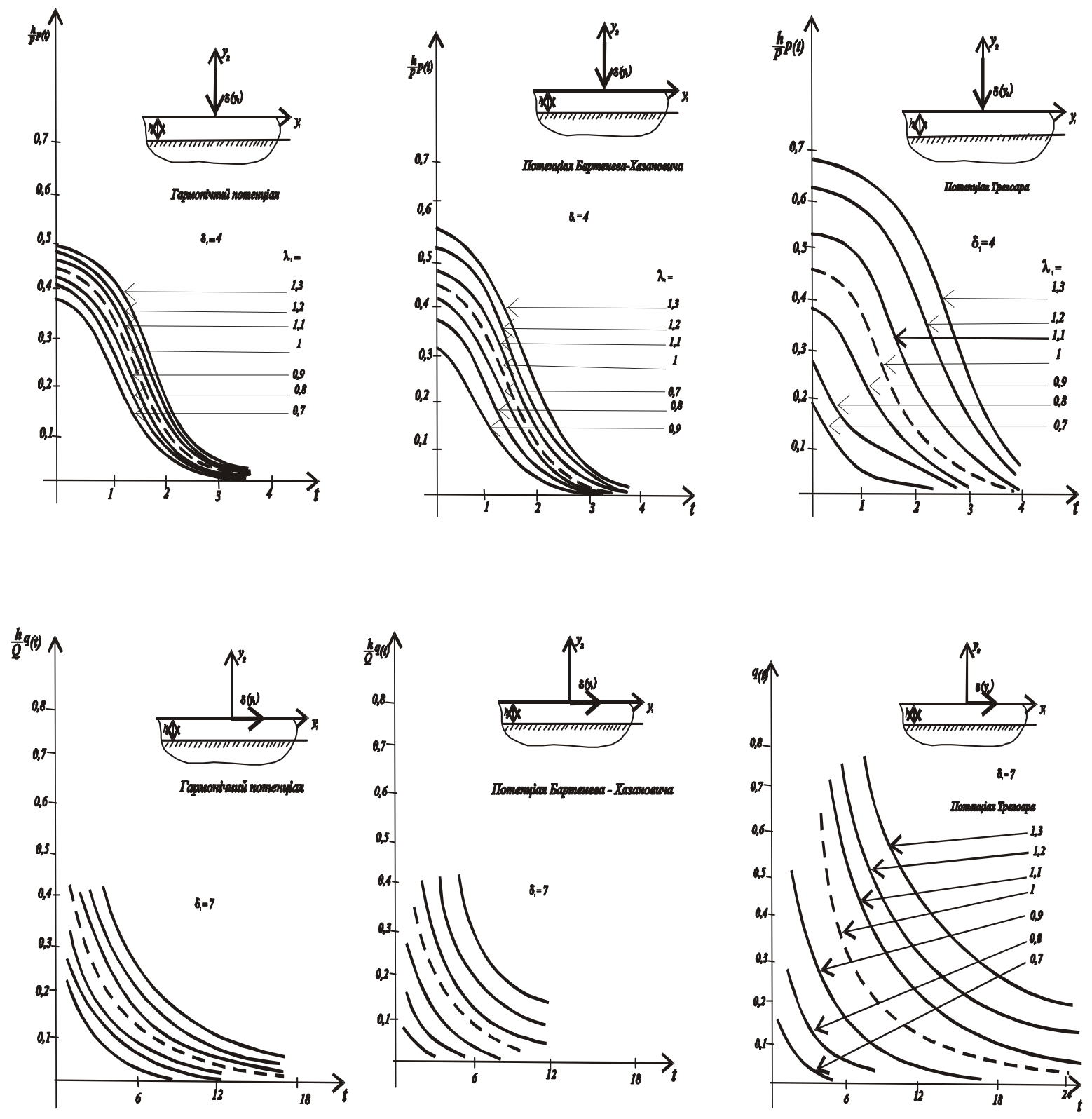

Fig. 3 - Distribution of the contact stresses under the stringer

Analysis of graphs is shows that in the case of compression $\left(\lambda_{1}<1\right)$, the presence of initial stresses in the elastic strip leads to a substantially decrease in the contact stresses, and in the case of stretching $\left(\lambda_{1}>1\right)-$ to increase them. From the graphs it follows that the effect of the initial stresses is stronger in highly elastic materials. 


\section{The strengthening of the strip a finite stringer}

In the framework of the linearized theory of elasticity and the formulation of the contact problems for

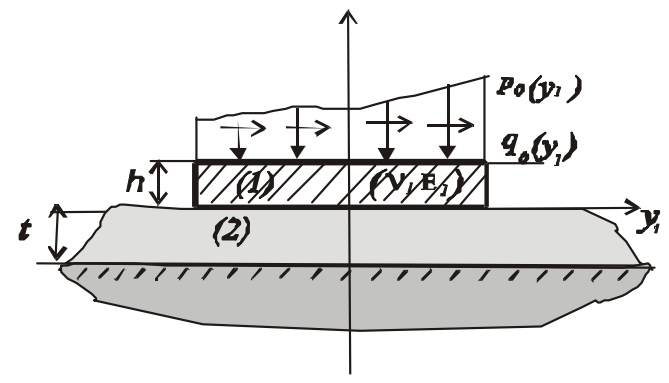

Fig. 4 - Strengthening of the strip by a finite stringer bodies with initial stresses, a contact problem for an elastic strip with initial (residual) stresses is reinforced with a thin finite elastic stringer is considered.

Consider the elastic strip with initial stresses of thickness $t$ which is clamped of the face $y_{2}=-t$ and on some finite part of the face $y_{2}=0$ is reinforced with a stuck (welded) stripe with an elastic thin stringer. The problem is formulated as follows: it is necessary to determine the effect of the initial (residual) stresses in the elastic strip on the law of distribution of the normal and tangential contact stresses within the contact area $[-a, a]$, if the stringer is loaded with vertical and horizontal external forces of intensity $p_{0}\left(y_{1}\right)$ and $q_{0}\left(y_{1}\right)$ (Fig. 4).

On the basis of the superposition principle in the case of equal and unequal roots of the defining equation, we obtain of the displacements:

$$
\begin{aligned}
& u_{1}\left(y_{1}\right)=\int_{-a}^{a} h_{11}\left(\left|y_{1}-\tau\right|\right) p(\tau) d \tau+\int_{-a}^{a} h_{12}\left(y_{1}-\tau\right) q(\tau) d \tau \\
& u_{2}\left(y_{1}\right)=\int_{-a}^{a} h_{21}\left(y_{1}-\tau\right) p(\tau) d \tau+\int_{-a}^{a} h_{22}\left(\left|y_{1}-\tau\right|\right) q(\tau) d \tau .
\end{aligned}
$$

Satisfying the boundary conditions (1) and with the equation (21) we obtain the basic system of functional equations, with which, after its solution, we find the contact stresses $p\left(y_{1}\right)$ and $q\left(y_{1}\right)$ :

$$
\begin{aligned}
& \frac{d}{d y_{1}}\left[\int_{-a}^{a} h_{11}\left(\left|y_{1}-\tau\right|\right) p(\tau) d \tau+\int_{-a}^{a} h_{12}\left(y_{1}-\tau\right) q(\tau) d \tau\right]=\frac{1}{D} \int_{-a}^{y_{1}} M_{2}(\tau) d \tau+F\left(y_{1}\right), \quad-a \leq y_{1} \leq b ; \\
& \frac{d}{d y_{1}}\left[\int_{-a}^{a} h_{21}\left(y_{1}-\tau\right) p(\tau) d \tau+\int_{-a}^{a} h_{22}\left(\left|y_{1}-\tau\right|\right) q(\tau) d \tau\right]=\frac{1}{E_{1} h}\left[Q_{2}\left(y_{1}\right)-Q_{1}\left(y_{1}\right)\right], \quad a \leq y_{1} \leq b .
\end{aligned}
$$

The system of singular integral-differential (22) equations is reduced to one singular integraldifferential equation if you introduce a complex-valued function in the form:

$$
\chi(x)=p_{1}(x)+i q_{1}(x) \quad(x=\xi, \eta, \zeta, \omega) .
$$
form:

Omitting cumbersome transformations [6], we write the singular integro-differential equation in the

$$
\begin{gathered}
\chi(\xi)+\frac{1}{r_{0}} \int_{-1}^{1} \frac{\chi(\eta)}{\eta-\xi} d \eta+\frac{1}{r_{0}} \int_{-1}^{1} \tilde{h}_{11}(\xi-\eta) \chi(\eta) d \eta \\
\frac{1}{r_{0}} \int_{-1}^{1} \tilde{h}_{22}(\xi-\eta) \bar{\chi}(\eta) d \eta-\frac{1}{\pi} \int_{-1}^{1} \tilde{h}_{12}(\xi-\eta) \bar{\chi}(\eta) d \eta+ \\
+c_{1} c_{2} \int_{-1}^{\xi} \int_{-1}^{1}[(\eta-\omega) \chi(\omega)+\bar{\chi}(\omega)] d \omega d \eta- \\
-i c_{2} \int_{-1}^{1}[\chi(\eta)-\bar{\chi}(\eta)] d \eta=2 c_{2} \varphi(\xi), \quad-1<\xi<1 .
\end{gathered}
$$

The solution of equation (22) will be sought in the form of a series of Jacobi polynomials $P_{n}^{(\alpha, \beta)}(\eta)$ :

$$
\chi(\eta)=w^{-1}(\eta) \sum_{n=0}^{\infty} \chi_{n} P_{n}^{(\alpha, \beta)}(\eta), \quad-1<\eta<1 .
$$


If in the singular integro-differential equation (24) replace the value of an unknown function $\chi_{n}$ on value (25), then, in accordance with the recurrence relation for the Jacobi polynomials and the orthogonality of Jacobi polynomials, we obtain an infinite system of linear algebraic equations:

$$
l_{m} X_{m}-\sum_{n=1}^{\infty} \frac{1}{n}\left(K_{m, n}^{(1)} X_{n}+K_{m, n}^{(2)} \bar{X}_{n}\right)=P_{m}^{(1)}-P_{n_{1}}^{(0)} C_{0}-P_{m}^{(3)} X_{0}-P_{m}^{(4)} \bar{X}_{n}, \quad(m=1,2 \ldots)
$$

After the calculations for specific materials, we obtain graphs of the distribution of loads under the stringer:
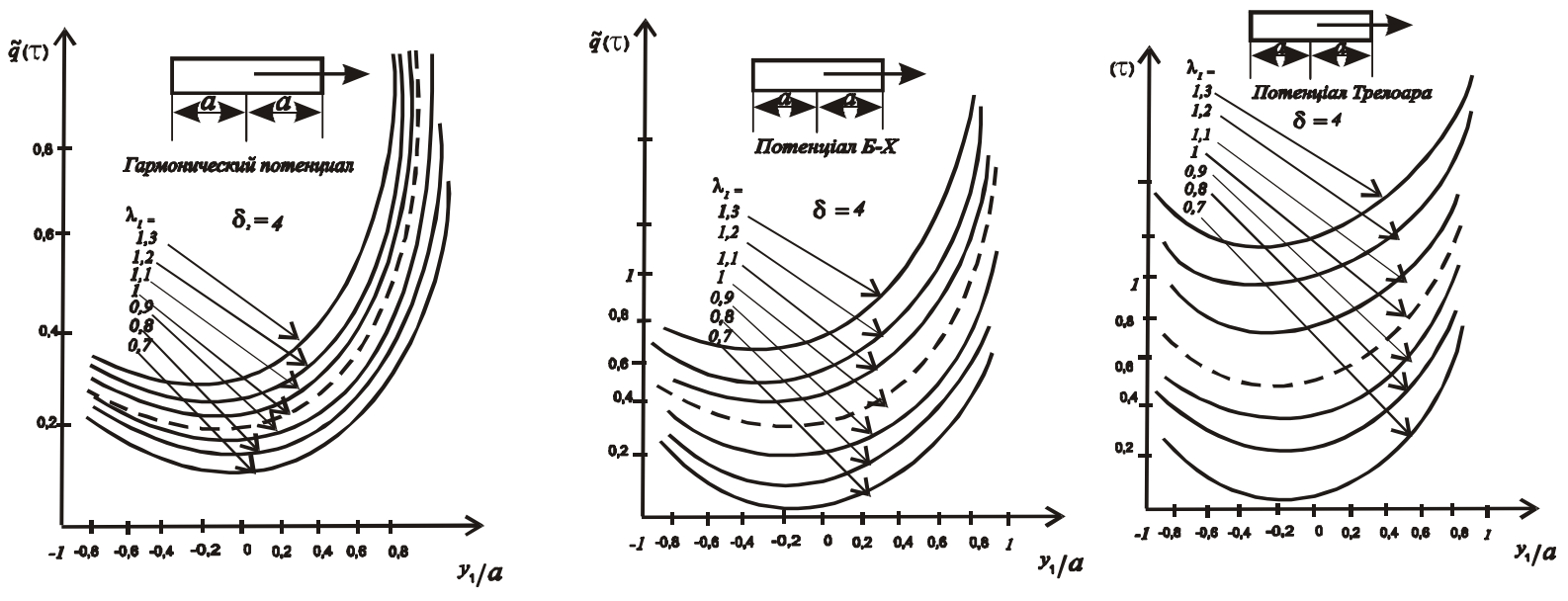

Fig. 5 - Distribution of loads under the finite stringers

The calculations were carried out for the dimensionless quantities of contact stresses $q^{*}=\frac{\delta_{2}}{\delta_{3}} \tilde{q}(\xi)$.

The results of calculations for the simplest elastic potentials of the harmonic, the BarthenevKhazanovich potential and the potential of Trelora are shown in the graphs (Fig. 5). The resulting numerical and graphical results were carried out using in the form of a computer program in the package Maple 8.

The dotted line shows the curves corresponding $\lambda_{1}=1$ to classical theory of elasticity, the curves corresponding $\lambda_{1}<1-$ shows the compressive initial stresses, $\lambda_{1}>1-$ shows the influence of tensile contact stresses for the $\delta_{2}=4$.

From the graphs it follows that the contact stresses on the contact line of the elastic strip with an elastic stringer substantially depend on the initial stresses. A more significant effect of quantitative nature, the initial stresses is caused in highly elastic bodies, compared with more stiffs (harmonic potential). The qualitative effect of the initial stresses is identical nature.

\section{Conclusions}

The studies presented in the paper allow us to make generalized conclusions of the influence of initial stresses on the law of distribution of contact forces under an infinite stringer

1. In general case for equal and unequal roots of the defining equation [1] the general method of solution for the problems considered within the framework of linearized theory of this class of problems is formulated. This gives an opportunity to get the solution of the set tasks, if known the solution of analogous linear (without initial stresses) problems.

2. The contact stresses on the contact line with stringer of significantly dependent on the initial stresses. A more significant effect of quantitative nature of initial stresses is caused in highly elastic materials compared with more stiffs materials. Qualitative effect of the initial stresses is identical nature.

3. When initial stresses is approximate to value corresponding to the surface instability, there are phenomena of "resonant" nature, which consist in the fact that the stresses and displacements in the field of contact a sharp of change their value, and the elastic strips with initial stresses are in a state of neutral equilibrium. 


\section{References}

1. Huz A.N. Kontaktnoe vzaymodeistvye upruhykh tel s nachalnыmy (ostatochnыmy) napriazhenyiamy / A.N. Huz, S.Iu. Babych, V.B. Rudnytskyi // Razvytye ydei L. A. Halyna v mekhanyke. K stoletyiu so dnia rozhdenyia uchenoho. - M. ; Yzhevsk : Yn-t kompiuter. yssled., 2013. - S. 188-244.

2. Huz A.N. Osnovы teoryy kontaktnoho vzaymodeistvyia upruhykh tel s nachalnыmy (ostatochnыmy) napriazhenyiamy [Tekst] / A.N. Huz, V.B. Rudnytskyi. - Khmelnytskyi: Yzd-vo "PP Melnyk", 2006. - 710 s.

3. Dykhtiaruk N.N. O ravnovesyy polosы s nachalnыmy napriazhenyiamy, usylennoi upruhymy nakladkamy / N.N. Dykhtiaruk // Prykl. mekhanyka. - 2004, - 40, № 3 - S. 63 - 70.

4. Dikhtiaruk M. M. Peredacha navantazhennia vid neskinchennoho strynhera do dvokh zatysnenykh po odnomu kraiu odnakovykh smuh z pochatkovymy (zalyshkovymy) napruzhenniamy / M. M. Dikhtiaruk // Visnyk TNTU. - 2016, - 83, № 3, -S. 51-60. 128 (1932)

5. E. Melan, "Ein Beitrag zur Theorie geschweiss der Verbindungen, “Ingenieur Archiv, 3, No. 2, 126-

6. Rudnytskyi, V. B., Dykhtiaruk N.N. Upruhaia polosa s nachalnыmy napriazhenyiamy, usylennaia upruhymy nakladkamy./ V. B. Rudnytskyi, N.N. Dykhtiaruk N.N. // Prykl. mekhanyka., 2002, - 38, № 11, S. $81-88$.

7. Rudnytskyi, V. B., Dykhtiaruk N.N. Kontaktnaia zadacha o vzaymodeistvyy beskonechnoho strynhera y dvukh odynakovыkh polos s nachalnыmy napriazhenyiamy. / V. B. Rudnytskyi, N.N. Dykhtiaruk N.N. // Prykl. mekhanyka., 2017, - 53, № 2, - S. $41-48$.

8. Dikhtyaruk, N.N. Equilibrium of a prestressed strip reinforced with elastic plates // International Applied Mechanics. - March 2004, Volume 40, Issue 3, pp 290-296.

9. Rudnitskii V.B., Dikhtyaruk N.N. A prestressed elastic strip with elastic reinforcements / V.B. Rudnitskii, N.N. Dikhtyaruk// International Applied Mechanics. - November 2002, Volume 38, Issue 11, pp 13541360.

10. Rudnitskii V.B. , Dikhtyaruk N.N. Interaction Between an Infinite Stringer and Two Identical Prestressed Strips: Contact Problem /, V.B. Rudnitskii, N.N Dikhtyaruk // Translated from Prikladnaya Mekhanika, Vol. 53, No. 2, pp. 41-48, March-April, 2017.

11. Dikhtiaruk M.M. Analoh zadachi Melana dlia pruzhnoi smuhy z pochatkovymy napruzhenniamy pidsylennoiu pruzhnoiu nakladkoiu [Tekst] / M. M. Dikhtiaruk, O. A. Poplavska // Problemy trybolohii. - 2018. - №1. - S. 37-42.

\section{Діхтярук М.М., Поплавська О.А., Курінєнко О.В. Контактна взаємодія пружної смуги з початковими напруженнями 3 нескінченим і скінченним стрингерами.}

Робота присвячена проблемам контактної взаємодії нескінченного і скінченого пружного стрингера 3 попередньо напруженою смугою. Дослідження проводилося в рамках лінеаризованої теорії пружності у загальній формі для теорії великих (кінцевих) початкових деформацій та двох варіантів теорії малих початкових деформацій 3 довільною структурою пружного потенціалу. Базуючись на припущенні, що стрингери завантажують одночасно вертикальні та горизонтальні сили, справедлива модель згину балки в поєднанні $з$ горизонтальним розтягом стрижня. Ця проблема сформульована математично як система інтегро-диференціальних рівнянь відносно невідомого контактних напружень. Використовуючи перетворення Фур'є, система розв'язується у замкнутому вигляді. Вирази напружень представлені інтегралами Фур'є досить простою структурою. Досліджено вплив початкових напружень на розподіл контактних напружень та виявлені механічні ефекти під дією зконцентрованих навантажень.

Ключові слова: лінеаризована теорія пружності, початкові (залишкові ) напруження, контактні задачі, інтегральні перетворення Фур'є. 